\title{
Casa Las Quemas
}

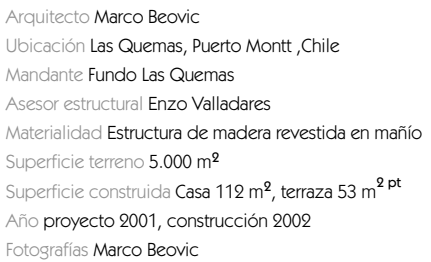

Esta casa está ubicada en el sector de Las Quemas, a $20 \mathrm{kms}$ de Puerto Montt, $1.000 \mathrm{kms}$ al sur de Santiago. El encargo es hecho por el dueño de un loteo de parcelas de $5.000 \mathrm{~m}^{2}$, cuya idea era vender una de las parcelas con casa. Ésta debía contemplar un programa típico, para una familia pequeña, y un presupuesto de construcción bajo. Se propuso un volumen único, un paralepípedo con un quiebre que crea una doble orientación y divide el programa público del privado. Las caras hacia el camino se presentan más cerradas y las posteriores se abren hacia la vista de los volcanes y hacia el norte, en busca de la mayor luz y del calor.
El techo se prolonga hacia este lado protegiendo de la lluvia y creando una terraza en todo el largo de la casa. La estructura fue pensada íntegramente en madera, con una retícula de $0.50 \times 0.50 \mathrm{~m}$ y cerchas como vigas. La casa se eleva del terreno con un sobrecimiento de hormigón retranqueado. El revestimiento exterior es de mañío, y el piso interior es de ulmo.

\section{Marcos Beovic}

Arquitecto, Universidad Católica de Valparaíso, 1997. Ha colaborado en las oficinas de Mathias Klotz y de Allen + Fulton Arqtos. Asoc. Paralelamente ha desarrollado proyectos de viriendas $y$ concursos de manera independiente.
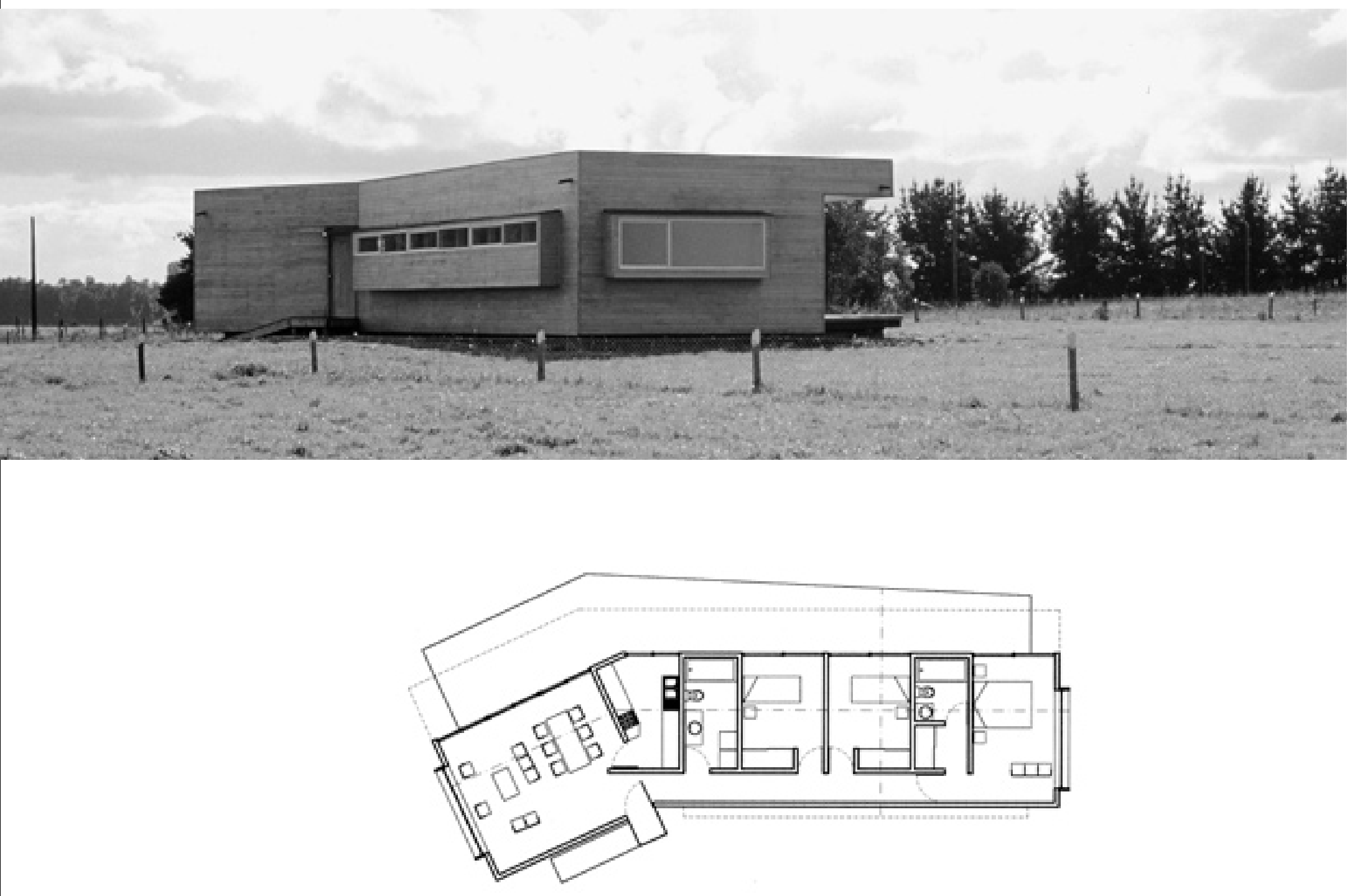

Planta general

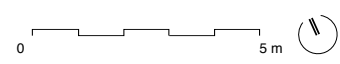

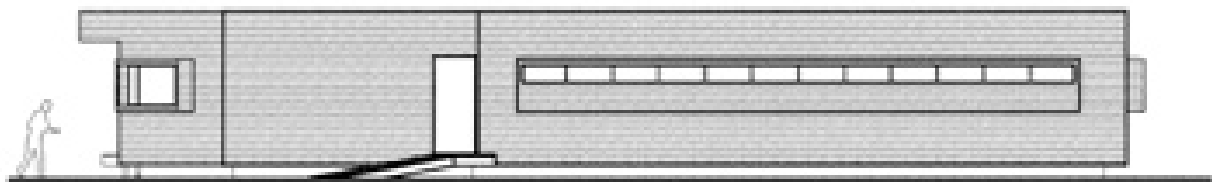

Elevación sur

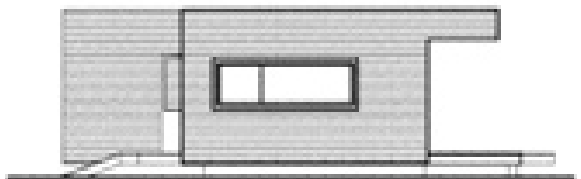

Elevación poniente 

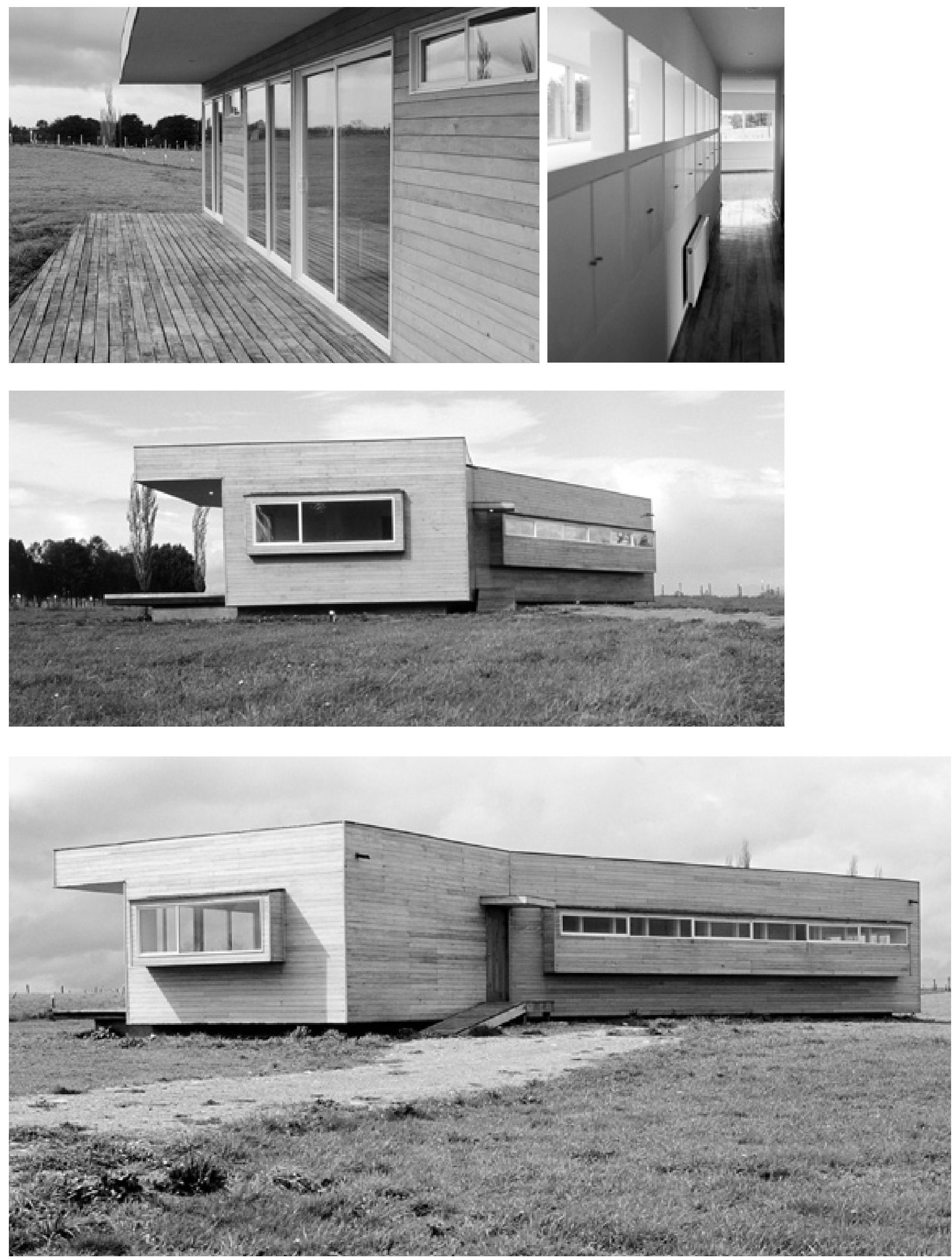